This item was submitted to Loughborough's Research Repository by the author.

Items in Figshare are protected by copyright, with all rights reserved, unless otherwise indicated.

\title{
On the theory of railway-induced ground vibrations
}

PLEASE CITE THE PUBLISHED VERSION

http://dx.doi.org/10.1051/jp4:19945167

PUBLISHER

(c) EDP Sciences 1994

VERSION

VoR (Version of Record)

LICENCE

CC BY-NC-ND 4.0

REPOSITORY RECORD

Krylov, Victor V.. 2012. "On the Theory of Railway-induced Ground Vibrations". figshare.

https://hdl.handle.net/2134/9670. 
This item was submitted to Loughborough's Institutional Repository (https://dspace.lboro.ac.uk/) by the author and is made available under the following Creative Commons Licence conditions.

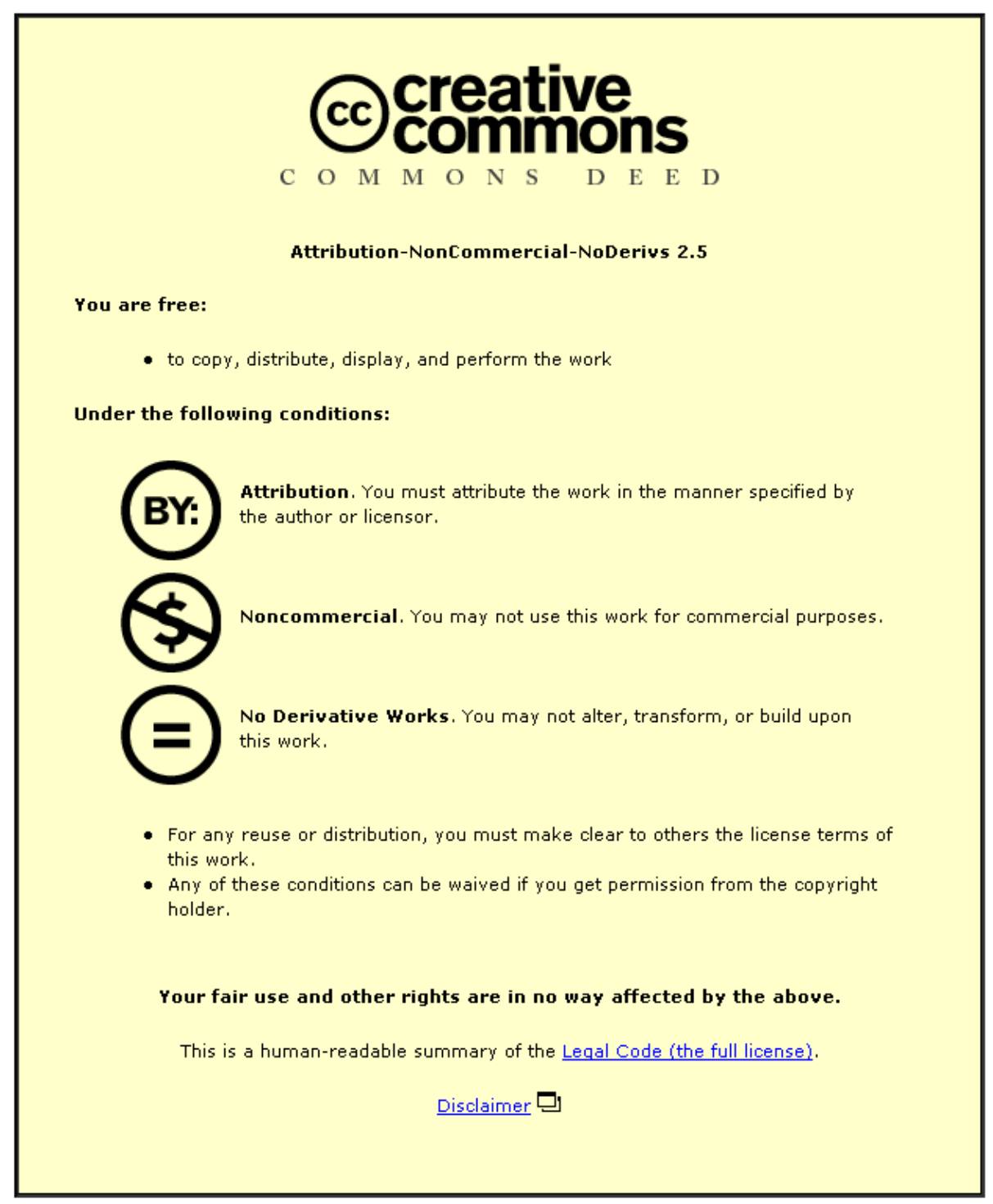

For the full text of this licence, please go to: http://creativecommons.org/licenses/by-nc-nd/2.5/ 


\title{
On the theory of railway-induced ground vibrations
}

\author{
V.V. KRYLOV \\ Centre for Research into the Built Environment, Nottingham Trent University, Burton Street, Nottingham \\ NG1 4BU, U.K.
}

\begin{abstract}
In the present paper, the theory of generation of ground vibrations by moving train is considered. The theory takes into account contribution of each sleeper of the track subjected to the action of all wheel axles. Mechanical properties of the track and parameters of train and soil (including static contact nonlinearity of track-soil system) are taken into account. It is shown that generated ground-vibration spectra depend strongly on the periodicity of track (distance between adjacent sleepers), parameters of the train (train speed, distances between wheel axles and carriages), and on the axle loads of the carriages. A special attention is paid to the ground vibrations generated by superfast trains. It is shown that tremendous increase of vibration level may occur if the train speed exceeds the velocity of Rayleigh surface wave in the ground. Such a situation is not a fantastic one and may really happen, e.g., in the case of TGV trains for which the speeds of $500 \mathrm{~km} / \mathrm{h}$ have been recently achieved on the experimental track in France. Simple methods of suppression of ground vibrations "on the track" are suggested.
\end{abstract}

\section{INTRODUCTION}

Railway-induced ground vibrations is one of the major factors of noise and vibration pollution in urban areas [1]. Spectra of railway-induced ground vibrations, including train-speed dependent components, have been studied experimentally by several authors [2-4]. However no rigorous theories have been developed so far, apart from the recent publications of C.C. Ferguson and the present author [5,6] who used the Green's function formalism to consider generation of ground vibrations by moving trains due to the impact of quasistatic pressure of wheel axles onto the track-soil system. In the case of welded rails and perfect wheels, this mechanism is the major contributor to trainspeed-dependent components of the low-frequency vibration spectra (up to $50 \mathrm{~Hz}$ ).

In this paper we give the outline of the theory of generating railway-induced ground vibrations by moving trains and describe some recent results obtained using this theory. A special attention is paid to the excitation of ground vibrations by superfast trains, in particular by those moving faster than Rayleigh surface waves in the ground.

\section{OUTLINE OF THE THEORY}

\subsection{Statement of the Problem}

We consider a train moving with speed $\mathrm{v}$ on welded track with sleeper periodicity $\mathrm{d}$. The excitation being considered results from load forces applied to the track from each wheel axle causing downward deflection of the track. For the low-frequency components of the spectra most relevant for ground vibrations, these deflections can be considered as quasi-static, producing a wave-like motion along the track with speed $v$ and resulting in a distribution of the axle load over all the sleepers involved in the deflection distance. Thus, 
each sleeper acts as a vertical force applied to the ground during the time necessary for a deflection curve to pass through the sleeper. This results in generation of elastic ground vibrations $[5,6]$. Since, in the relevant frequency band, the characteristic wave-lengths of generated elastic waves are much larger than the sleeper dimensions, each sleeper can be considered as a point-source vertical force.

An important aspect of the above is calculation of the track deflection curve as a function of the magnitude of the axle load. The form of the deflection curve, being dependent on the axle load magnitude, determines the ground vibration frequency spectrum generated by each sleeper. In turn, these spectra strongly affect the total vibration spectrum generated by a passing train.

\subsection{Green's Function Formalism}

To calculate the vibration field radiated by a moving train requires the superposition of fields generated by each sleeper activated by all axles of all carriages, with the time and space differences between sources (sleepers) being taken into account.

Using the Green's function formalism, the vertical component of the ground vibration velocity spectra on the ground surface $(z=0)$ may be written in the form

$$
v_{z}(x, y, \omega)=\int_{-\infty-\infty}^{\infty} \int^{\infty} P\left(x^{\prime}, y^{\prime}, \omega\right) G_{z z}(\rho, \omega) d x^{\prime} d y^{\prime}
$$

where $G_{z z}(\rho, \omega)$ is the corresponding component of the elastic Green's tensor (Green's function) for the elastic semispace (see, e.g. [7]), $\rho=\left[\left(y-y^{\prime}\right)^{2}+\left(x-x^{\prime}\right)^{2}\right]^{1 / 2}$ is the distance between the point of observation $\{x, y\}$ and the elementary source $\left\{x^{\prime}, y^{\prime}\right\}, P\left(x^{\prime}, y^{\prime}, \omega\right)$ describes the total distribution of forces along the track. This distribution is being found by taking a Fourier transform of the time and space dependent track deflection function (see $[5,6]$ ).

\subsection{Ground Vibrations from Moving Train}

It is useful firstly to consider a single axle load moving with speed $\mathrm{v}$ along the track directed along the axis $y$ and lying on perfectly elastic ground. Then the load force distribution which makes a wave-like motion along the track may be written in the form

$$
P\left(t, x^{\prime}, y^{\prime}=0\right)=\sum_{m=-\infty}^{\infty} P\left(t-x^{\prime} / v\right) \delta\left(x^{\prime}-m d\right) \delta\left(y^{\prime}\right)
$$

where $P\left(t-x^{1} / v\right)$ describes time dependence of force applied to the ground from each sleeper (it depends nonlinearly on the axle load), $\mathrm{m}$ is the number of current sleeper, Dirac's delta-function $\delta$ ( $\left.\mathrm{x}^{\prime}-\mathrm{md}\right)$ takes the periodic distribution of sleepers into account. Taking a Fourier transform of (2) and substituting it into eqn (1) yields the following expression for the vertical surface vibration velocity of Rayleigh waves generated at $\mathrm{x}=0, \mathrm{y}=\mathrm{y}_{0}$ by a single axle load:

$$
\mathrm{v}_{\mathrm{z}}\left(\mathrm{x}=0, \mathrm{y}=\mathrm{y}_{0}, \omega\right)=-\mathrm{iV}(\omega) \sum_{m=-\infty}^{\infty} \exp \left[\mathrm{i}(\omega / \mathrm{v}) \mathrm{md}+\mathrm{i}\left(\omega / \mathrm{c}_{\mathrm{R}}\right) \rho_{\mathrm{m}}\right] / \sqrt{\rho_{\mathrm{m}}}
$$

where $\rho_{\mathrm{m}}=\left[\mathrm{y}_{0}{ }^{2}+(\mathrm{md})^{2}\right]^{1 / 2}$ is the distance between sleeper with a number " $\mathrm{m}$ " and the point of observation, $V(\omega)$ is the function proportional to the Fourier transform of $P(t)$ and to the elastic parameters of the ground (see [5,6] for the details). It follows from eqn (3) that a single moving load generates a quasi-discrete spectrum with frequency peaks close to $f_{p} s$, where $f_{p}=v / d$ is the so called passage frequency $(s=1,2,3 \ldots)$. Deviation from perfect discreteness results from the $i\left(\omega / c_{R}\right) \rho_{m}$ term in eqn 
(3) which takes into account path-length differences of waves propagated from each sleeper to the point of observation.

Taking account of all axles and carriages of a moving train results in the following expression for the frequency spectra of vertical vibrations at $z=0$ :

$$
\begin{aligned}
\mathrm{v}_{\mathrm{z}}\left(\mathrm{x}=0, \mathrm{y}=\mathrm{y}_{0}, \omega\right)= & -\mathrm{iV}(\omega) \sum_{m=-\infty}^{\infty} \sum_{n=0}^{N-1} \mathrm{~A}_{\mathrm{n}}\left[\exp \left(-\gamma \omega \rho_{\mathrm{m}} / \mathrm{c}_{\mathrm{R}}\right) / \sqrt{ } \rho_{\mathrm{m}}\right][1+\exp (\mathrm{iM} \omega / \mathrm{v})] . \\
& \exp \left(\mathrm{i}(\omega / \mathrm{v})(\mathrm{md}+\mathrm{nL})+\mathrm{i}\left(\omega / \mathrm{c}_{\mathrm{R}}\right) \rho_{\mathrm{m}}\right) .
\end{aligned}
$$

Here $\mathrm{N}$ is the number of carriages, $\mathrm{M}$ is the distance between bogies in each carriage and $\mathrm{L}$ is the total carriage length (values of $\mathrm{M}, \mathrm{L}$ as well as $\mathrm{d}$ may have essential random components). Dimensionless quantity $A_{n}$ is an amplitude weight-factor to account for different carriage masses. In writing eqn (4) we account for attenuation in soil by replacing $1 / c_{R}$ in the exponentials by the complex value $1 / c_{R}+i \gamma / c_{R}[8]$, where $\gamma \ll<1$ is a constant describing the "strength" of dissipation of Rayleigh waves in soil [9].

It follows from eqn (4) that spectra of train-induced ground vibrations are quasi-discrete, with the maxima at frequencies determined by the condition $(\omega / \mathrm{v})(\mathrm{md}+\mathrm{nL})=2 \pi \mathrm{l}$, where $1=1,2,3, \ldots$. Obviously, $n=0$ corresponds to the passage frequencies $f_{p} s$ determined by the sleeper period $d$. Other more frequent maxima are determined either by the carriage length $L \quad(m=0)$ or by a combination of both parameters (for $n \neq 0, m \neq 0$ ). Note that for very heavy axle loads, which may cause the peripheral bulges and loss of contact between the track and soil, the high frequency components of the spectra are more pronounced.

\section{SUPPRESSION OF GROUND VIBRATIONS AT PASSAGE FREQUENCIES}

In addition to the frequency peaks, there are also many zeros in the train vibration spectra (4). These zeros may be used in practice for suppressing vibrations at chosen frequencies $[5,6]$. The most important zeros are those which do not depend on a number of sleepers or carriages and are determined only by the parameters of a carriage. One of these zeros is determined by the distance a between the wheel axles in a bogie: $f_{z}=(v / a)(n+1 / 2)$. If, for instance, we want to suppress one of the train passage frequencies $f_{p} s$, we should choose $f_{z}$ to be equal to $f_{p}$ s. It follows from this that the value of a should be determined by

$$
a=(d / s)(n+1 / 2) .
$$

It is sensible to choose a value of a close to existing values. E.g., for British Rail heavy-freight carriages $\mathrm{a}=2.2 \mathrm{~m}$ usually. Therefore, to suppress the main passage frequency ( $\mathrm{s}=1$ ) one can chose $\mathrm{a}=2.45 \mathrm{~m}$ corresponding to $n=3$ in eqn (5). This gives the ground vibration suppression by $20 \mathrm{~dB}$.

Other important zero frequencies reflect the distance $M$ between bogies in a carriage. Condition (5) is also valid for this case if $a$ is replaced by $M$. The value of $M$ providing suppression of the main passage frequency that is closest to the British Rail standard $(M=4.88 \mathrm{~m})$ is $4.55 \mathrm{~m}$, corresponding to $\mathrm{n}=6$. It is possible, of course, to adjust the period of sleepers $d$ to satisfy eqn (5).

\section{GROUND VIBRATIONS FROM SUPERFAST TRAINS}

Continuous increase of train speeds on European railways makes it inevitable to consider the environmental impact of such trains. From the point of view of generating ground vibrations, especially vulnerable are superfast trains approaching the "sound barrier" with regard to the velocity of Rayleigh surface waves $c_{R}$ propagating in the ground. In May 1990, nine runs of TGV trains at over $500 \mathrm{~km} / \mathrm{h}$ (i.e., over $139 \mathrm{~m} / \mathrm{s}$ ) were made by SNCF on the section of the track between Courtalain and Tours in France. These speeds are larger than velocities of Rayleigh waves in soft soils $(90-130 \mathrm{~m} / \mathrm{s})$. Hence, the radiation effects for ground vibrations similar to those of Mach radiation of shock waves by supersonic jets might be expected. 
To discuss the principal aspects of the problem, we consider a single load moving along the track with the speed $v>c_{R}$. Let the point of observation be arbitrary located on the surface, i.e. $\rho_{m}=\left[y^{2}+(x-m d)^{2}\right]^{1 / 2}$. For the far zone we have $\rho_{m} \approx R-m d \cos \Theta$, where $R=\left[y^{2}+x^{2}\right]^{1 / 2}$ and $\cos \Theta=x / R$. Substitution of the far zone value of $\rho_{m}$ into eqn (3) shows that the condition of maximum radiation takes place for $\cos \Theta=c_{R} / v$. This is similar to the corresponding condition of Mach radiation in aerial acoustics. Since the radiation angle $\Theta$ should be real $(\cos \Theta \leq 1)$, this implies that $v$ should be larger than $c_{R}$. In this case the ground vibrations are generated as plain waves symmetrically propagating at the angles $\Theta$ versus the track, their intensity being much larger in comparison with the case of relatively slowly moving trains (see the Figure). We must note, however, that since the radiation angle $\Theta$ is usually small enough, some special mitigation procedures based on the waveguide effects can be applied to the railway lines to trap the vibration energy close to the track.
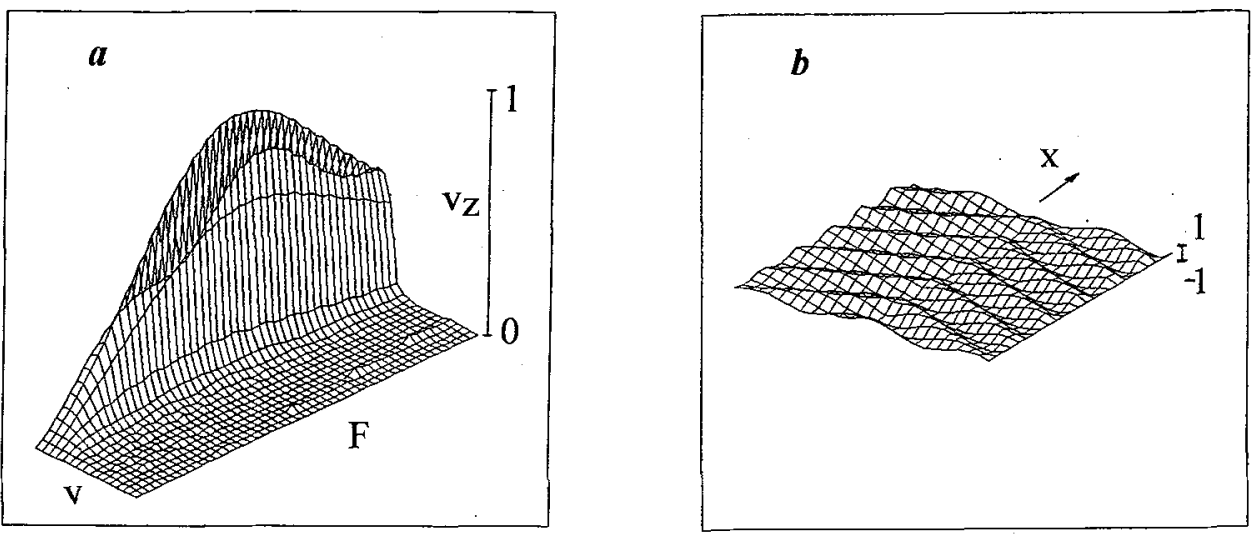

\section{Ground vibrations from superfast trains}

a) Generated ground vibrations as function of frequency $F$ and train speed $v$ : axle load $-100 \mathrm{kN}, \mathrm{c}_{\mathrm{R}}=125 \mathrm{~m} / \mathrm{s}, \Delta \mathrm{F}=1 \mathrm{~Hz}, \Delta \mathrm{v}=10 \mathrm{~m} / \mathrm{s}, \mathrm{y}_{0}=30 \mathrm{~m}$;

b) Space distribution of radiated field: $v=139 \mathrm{~m} / \mathrm{s}, \quad c_{R}=125 \mathrm{~m} / \mathrm{s} ; \quad F=20 \mathrm{~Hz}$

\section{REFERENCES}

[1] Okumura Y. \& Kuno K., Applied Acoustics, 33 (1991) 263-280.

[2] Dawn T.M., J. Sound and Vibr., 87 (1983) 351-356.

[3] Volberg G., J. Sound and Vibr. 87 (1983) 371-376.

[4] Melke J., J. Sound and Vibr. 120 (1988) 391-406.

[5] Krylov V.V. and Ferguson C.C., Proc. Inst. of Acoustics (UK), 15, Part 8 (1993) 59-68.

[6] Krylov V. and Ferguson C., Applied Acoustics (to appear).

[7] Krylov V.V., J. of Phys. D: Appl. Phys., 25 (1992) 155-161.

[8] Krasil'nikov V.A. and Krylov V.V., Introduction to physical acoustics (Nauka, Moscow, 1984 - in Russian). 400 pp.

[9] Gutovski T.G. and Dym C.L., J. Sound and Vibr. 49 (1976) 179-193. 